Article

\title{
Minimizing the Gap between Expectation and Ability: Strategies for SMEs to Implement Social Sustainability Practices
}

\author{
Priyabrata Chowdhury* and Rezaul Shumon \\ School of Accounting, Information Systems and Supply Chain, RMIT University, \\ Melbourne, Victoria 3000, Australia; rezaul.shumon@rmit.edu.au \\ * Correspondence: priyabrata.chowdhury@rmit.edu.au
}

Received: 30 June 2020; Accepted: 7 August 2020; Published: 9 August 2020

check for updates

\begin{abstract}
Traditionally, it is believed that small- and medium-sized enterprises (SMEs) do not have enough ability to adopt and persistently practice social sustainability. This is because SMEs are not capital-intensive companies and neither are their returns nor skills. At the same time, the wellbeing of the employees in SMEs cannot be ensured and sustainable development goals cannot be achieved without making SMEs socially sustainable, as they account for the majority of world businesses. Moreover, the expectation of the stakeholders and subsequent pressure on SMEs to practicing social sustainability remains. Such pressure from the stakeholders creates a "mismatch problem" between stakeholders' expectations and SMEs' abilities to adopt socially sustainable practices. This study aims to explore what factors are responsible for this "mismatch problem", and how SMEs can handle this mismatch to be socially sustainable firms. Based on a rigorous literature review, this study reveals that both internal issues, such as a lack of resources and awareness, and external issues, such as the non-existence of a tailored social sustainability standard for SMEs and lack of institutional support, are responsible for this gap. This study develops several propositions that highlight the requirements in various situations and provides strategies outlining the implications for SMEs and their stakeholders to make SMEs socially sustainable. Overall, this study discloses that cooperative support from stakeholders, especially during a disruption such as the COVID-19 pandemic, a finance mechanism, the development of awareness and human capital in SMEs, and a unified standard for SMEs are likely to improve social sustainability practices in SMEs.
\end{abstract}

Keywords: social sustainability; small- and medium-sized enterprises (SMEs); stakeholder support; social sustainability awareness

\section{Introduction}

There has been a widespread agreement that achieving social sustainability is critical for businesses, organizations, and society [1,2]. Big companies and corporations have traveled far towards attaining their goal of implementing social sustainability practices (SSPs). However, small- and medium-sized enterprises (SMEs) are falling significantly behind in terms of achieving social sustainability goals $[3,4]$. While the advancement of multi-national and big corporations in this regard is appreciable, nonetheless, the full benefit of social sustainability cannot be realized by society unless SMEs implement SSPs, as these smaller firms account for the majority of the businesses in all countries around the world. For example, more than 99 percent of European enterprises are SMEs, generating more than 85 percent of new employment in Europe [5]. Therefore, it is obvious that achieving social sustainability in SMEs will be vital for society as a whole. It has also been established that socially sustainable companies generally perform better than other companies that do not adequately maintain these practices, 
as these non-participating firms suffer from a negative reputation and a loss of brand value [6,7]. Therefore, practicing social sustainability is important for SMEs to maintain their competitiveness $[8,9]$.

Although research on social sustainability in SMEs is not well explored and still at a nascent stage, a notion can be extracted from the literature that indicates SMEs' inability to adopt SSPs. Many factors can be cited as responsible for such an inability. For example, a lack of finance and capital investment, knowledge, skills, and awareness and the misperceptions of SME owners and managers regarding their role are predominantly mentioned in the literature $[10,11]$. No matter what the factors are, stakeholder expectations and subsequent pressures for SSPs in SMEs are inevitable. This creates a gap between the expectation of stakeholders and the ability of SMEs to implement SSPs in the supply chain or business environment. Therefore, it is important to comprehensively understand this gap, which has been termed in this study as a "matching problem", and to formulate appropriate strategies to reduce the gap. Due to the lack of focus on SMEs, the current body of literature is unable to provide such understandings. On the other hand, underlying factors in adopting SSPs are different in multinational or large companies and SMEs [4], suggesting that knowledge on social sustainability in the context of large firms is not readily applicable to SMEs. Therefore, studies are particularly needed in the context of SMEs to understand the "matching problem" and to formulate strategies to handle the problem.

In this study, therefore, we aim to provide an understanding of this issue. Based on a rigorous literature review, we first explore the factors responsible for creating the gap between stakeholder expectation and SMEs' abilities to adopt SSPs. Then, we find strategies to reduce the gap so that SMEs can be socially sustainable. In designing the strategies, we also outline the role of SMEs and various stakeholders, such as buyers, government, and NGOs involved in the implementation of social sustainability requirements in SMEs. By doing so, the study contributes to the literature on social sustainability, as well as on SMEs. More importantly, we believe the study findings can serve as a guide for SMEs and their stakeholders in formulating strategies to enhance SSPs in these smaller firms.

The rest of the paper is structured as follows. Section 2 outlines the concept and necessity of social sustainability in SMEs. Section 3 introduces the "mismatch problem" and Section 4 explores it further and develops propositions to understand why it exists in SMEs and how various factors contribute to handling this problem. In line with the propositions, Section 5 provides the strategies and outlines the role of SMEs and their stakeholders to make SMEs socially sustainable. The contributions of the study are highlighted in Section 6, and a concluding remark, along with the future research directions, are provided in Section 7 .

\section{Social Sustainability in SMEs}

Supply chain social sustainability is concerned with the human side of sustainability $[3,12,13]$. It refers to the practices and ways firms address issues related to the health, safety, career progression initiatives, freedom, and welfare of the people associated with the supply chain [1]. In an attempt to specify the SSPs, Wolf [14] mentioned nine (9) main indicators: (1) a healthy and safe work environment, (2) an acceptable minimum wage, (3) the specification of maximum work hours, (4) freedom to join an employee union, (5) a policy for child labor, (6) suitable living conditions, (7) non-discrimination, (8) a clear policy for corporate disciplinary practices, and (9) a policy for forced labor. In addition to the organizational side, social sustainability is also concerned about advocating for the local community and culture. For example, according to Zhang and Zhang [15], social sustainability addresses issues relating to respecting, protecting, and advocating for native cultures and communities via providing benefits to neighboring residents and actively participating in various community functions. More specifically, firms can engage in several local programs on health, education, and sports via developing these services or collaborating with the existing local providers to help the low-income earners of the community [16]. From the social sustainability perspective, participating in these functions is generally considered as an intervention towards the enrichment of the society and community development $[8,17]$.

Valuing and practicing SSPs are important for all firms, including SMEs. The importance for SMEs is twofold: (1) SMEs can improve various performances by practicing SSPs efficiently and (2) the active 
participation of SMEs in SSPs is required to reach overall social sustainability goals from the societal perspective. By being socially sustainable, SMEs can enjoy tangible performance improvements [18]. For example, Mani, Jabbour, and Mani [4] found that SSPs contribute to improvements in the supply chain performance of SMEs. Moreover, the study revealed that the higher the investment made by SMEs in SSPs, the better their supplier performance, customer performance, and operational performance. These SSPs also significantly improve the financial performance of SMEs and enhance customer satisfaction and employee satisfaction [16]. Moreover, SMEs' opportunities to improve innovation are increased when they can integrate SSPs with their core business policies and strategies [19], as well as with other operations of the organization [9]. In addition, the integration of workforce-oriented and society-oriented sustainability practices has a positive impact on the overall competitiveness of SMEs [8]. Lee, Che-Ha, and Alwi [9] also argued that SSPs enhance the competitive advantage of SMEs. Furthermore, the implementation of adequate SSPs enhances the reputation of SMEs in societies and communities [20].

The adoption of SSPs by SMEs is also important from the societal point of view. Complete social sustainability cannot be achieved if it is only practiced by large organizations as, in some economies, such as EU countries and Malaysia, more than 99 percent of businesses are SMEs [21,22]. In addition to adopting SSPs in workforce management, SMEs can play a substantial role in achieving complete sustainability via focusing on local development by employing from surrounding areas and solving local problems, as they generally manage niche social resources [19]. Moreover, SME operations have substantial impacts on societies due to their large numbers. Therefore, their active participation in SSPs is essential for overall social sustainability development [10,23].

While SSPs in SMEs are necessary from both SME and societal points of view, SMEs find it challenging to implement and generally consider these practices as elective $[9,10]$. They perceive that the potential benefits of SSPs are far less than the cost associated with their implementation [24]. Although they are not under the intense scrutiny of stakeholders, stakeholder's expectations remain a pressure for SMEs, which creates a mismatch between their abilities and expectations. Through an extensive literature review, this research has identified a "mismatch problem", which is yet to be investigated in the literature. The objective of this study is to materialize the mismatch problem and seek potential solutions to be carried out.

\section{What Is the Mismatch Problem?}

There is a growing concern among stakeholders about implementing sustainability practices in the SME sector. Although the perception of SMEs is that they have a little individual impact on the environment [25], collectively, their impacts are very high [26]. So, it is expected that this sector will step forward to make their operations sustainable. Stakeholders around the world are taking measures, such as new legislation, to force SMEs to behave ethically, collaborating with them by educating them on social sustainability issues, providing direct or indirect incentives or rewards, and so on. However, the concern within SMEs is how a single economic entity, especially a small-scale enterprise, can be engaged in the uptake of sustainability practices. It is known that SMEs have a lack of expertise and understanding with regard to strategies to address social and environmental issues [27]. This can further be elaborated into many other issues faced by SMEs, such as the cost of implementation and the limited capacity to absorb the cost within the volume of their operation. It is well known that cost is a major barrier for SMEs to show more proactive sustainable behavior, with mangers perceiving little financial benefit from environmental investments. This is even more exacerbated by little or no access to finances from banks and other investment corporations, as they tend to favor large organizations due to credit rating history and wealth. A lack of awareness regarding sustainability practices among SMEs is evident, especially in the least developed or developing countries, where cultural factors play a big role [10]. In many countries, children are employed in SMEs rather than going to school because the legislation does not work fully due to cultural issues. The health and safety of workers and workplaces are also among the things with the least priority. Despite all these issues limiting 
SMEs' abilities to take up social sustainability issues, stakeholders' expectations are still increasing. Therefore, there is a clear mismatch between the expectations of stakeholders and the reality of SMEs' abilities to meet those expectations. We envisage that this mismatch between expectation and reality could hinder the progress of social sustainability implementation in SMEs and thus we investigate further. Accordingly, we aim to explore the following research questions:

i. Why there is a gap between stakeholders' expectations and SSPs adopted by SMEs?

ii. What should be the strategies to minimize the gap?

\section{Exploration of the Mismatch Problem in SMEs}

\subsection{Factors Responsible for the Gap in SMEs' SSPS}

The literature suggests a number of reasons why there is a social sustainability gap in SMEs. Among them, a lack of various types of resources, such as finances, skills, staff, and time, are mentioned most frequently $[9,10,28]$. A lack of financial resources to invest in implementing sustainable practices is considered one of the main barriers to adopting SSPs in SMEs $[27,29,30]$. The initial investment is required for several SSPs, such as building infrastructure for a safe work environment. While SMEs have a lack of infrastructure, they also cannot only make compliance investments to build such infrastructure due to a lack of financial resources [19]. As such, SMEs are unable to implement several SSPs in their firms. Moreover, an efficient implementation of SSPs requires appropriate skills in the labor force and managers that may not be adequate in SMEs [19,31]. The lack of skills in SMEs is evident in the findings in Johnson and Schaltegger [10], who report that, even when SMEs are aware of the impacts and benefits of SSPs, they are still unable to implement these practices properly due to a lack of skills, knowledge, and expertise. In line with this, a recent study [32] also suggests that practitioners and leaders in SMEs need to be skilled to properly implement SSPs. Furthermore, SMEs generally have too few human resources (staff) to assign someone specifically to the job of taking care of social sustainability or sustainability issues. Due to wearing different hats within a business, SME practitioners also face time constraints in implementing social sustainability indicators [33]. For example, according to the Chamber of Commerce, Industry, Craft and Agriculture of Milan (2003), while more than 80 percent of SMEs with five to nine employees are not willing to implement SSPs, this percentage drops substantially when the results are analyzed for SMEs with 10 or more employees (cited in [24]).

In addition to a lack of resources, a lack of long-term orientation, and the misperceptions of SME owners and managers are mentioned as barriers to adopting SSPs. The investment made in improving SSPs does not provide sufficient return in the short to medium term [24]. However, SMEs care more about the investment that gives them immediate returns, as they do not value the investment that only provides benefits in the long term $[34,35]$. As a result, smaller firms perceive very few benefits of sustainability practices compared to larger firms [36]. Moreover, SMEs generally lack a consistent and proactive sustainability culture to promote SSPs. Given that such culture and orientation are important for all firms, including SMEs, in adopting both basic and advanced SSPs [37-39], a lack of these elements certainly creates obstacles in the implementation of these practices. In addition, while SMEs are characterized by a small number of employees, they also have a high degree of necrocracy, as they are mostly family businesses where conflict among family members is a common issue [40]. Due to these conflicts, it is difficult for firms to reach a consensus for implementing a social practice unless there exists an established culture and formal governance mechanism for SSPs [41,42]. The other barrier is that SMEs often perceive that their operations have no or minimal impacts on society [30]. However, research shows that the cumulative impacts of SME operations are very high, as most of the businesses across the world are SMEs [26]. These misperceptions are found to be counterproductive to adopting SSPs $[10,11,23]$.

While SMEs' lack of resources and poor social sustainability orientations are mostly mentioned as the barriers to adopting SSPs in the literature, we dig deeper into the SME literature to understand 
if any other factors are also responsible for the gap between stakeholders' expectations and SMEs' SSPs. It is important to understand this because some SMEs successfully implement SSPs [43]. If some can, a common question is what makes the gap bigger for other companies. Moreover, both resources and orientation are internal issues of SMEs. Highlighting only these issues means that the blame is on SMEs for the social sustainability gap in their firms. The literature survey reveals that SMEs face problems in finding guidelines for implementing a social sustainability standard that is specifically designed for them [24]. This is a crucial factor for increasing SSPs in SMEs because many guidelines are set in the context of large multi-national companies and may not be applicable for SMEs [44].

The other issue that increases the gap is the lack of support from other stakeholders in implementing SSPs. Due to their smaller size, the business counterparts of SMEs, such as buyers and suppliers, often consider them less critical; hence, they provide limited support in implementing SSPs. Moreover, SMEs do not have enough bargaining power [23], which is required to solicit support from other supply chain partners in complying with social sustainability standards [45]. Due to limited bargaining power, SMEs are also not able to provide requirements to their supply chain partners to ensure supply chain-wide social sustainability. For example, Jorgensen and Knudsen [29] found that SMEs receive more social sustainability requirements from their buyers than they provide to their immediate suppliers. Due to the lack of support from their supply chain partners or other relevant stakeholders, SMEs tend to ignore SSPs.

As discussed, many issues are responsible for the social sustainability gap in SMEs. These include several internal issues, such as the resource, skill, and knowledge constraints of SMEs and the poor orientation culture of SMEs, as well as external issues, such as the complexity of the standards and a lack of stakeholder support. Therefore, we come up with the following proposition:

Proposition 1 (P1). Both internal factors, such as a lack of resources and poor social sustainability orientation and culture, and external factors, such as a lack of standard and institutional support from various stakeholder groups, are responsible for the gap between stakeholders' expectations and SSPs adopted by SMEs.

\subsection{Role of Stakeholder Pressure and Support}

Stakeholder pressure has been considered as a dominant factor for firms to implement sustainable practices in their organizations. However, as big organizations are under the intense scrutiny of stakeholders, such as government, media, NGOs, and so on, they generally act on the requirements of their stakeholders. This is because they tend to have the necessary capabilities to implement such practices. However, not all organizations will be able to integrate these into their business practices, particularly when it concerns SMEs [9]. Although SMEs are a significant driver of economic growth, wealth, and job creation [22], their lack of awareness and interest in sustainability is well acknowledged in literature [10]. Furthermore, SMEs are generally not under the attention of the media or other stakeholders and so enjoy less accountability for their activities in society. As they operate below the radar screen of regulators and the general public, they can easily escape public scrutiny. Strict regulations are sometimes considered as a possible option to make firms comply with sustainability issues.

Although legislation could drive SMEs to engage in sustainability activities, legislative pressure, or other forms of pressure, alone is not enough because of the poor surveillance of sustainability activities in developing countries. For instance, research by Baden, Harwood, and Woodward [46] found that pressure by government and big organizations to include social sustainability requirements in procurement works as an incentive for only $49 \%$ of SMEs. Moreover, because SMEs' prime concern is general competitiveness and a preference for short-term monetary benefits, it has become very complex for policymakers to set up a proper policy for SMEs to adopt sustainable practices. As a result, mere pressure from government and policymakers cannot substantially improve SSPs in SMEs. In addition, SMEs only strive to meet the requirements of their immediate partners, especially powerful 
ones, in the supply chain [47]; hence, any pressure that comes from other supply chain partners does not work profoundly for the implementation of SSPs.

Instead, support from stakeholders can work better to motivate SMEs to implement SSPs. Many governments and business associations across the globe have reward packages, policy support, and other schemes to encourage SMEs to implement SSPs [48]. A number of schemes, such as the "Living Business Programme" and "Caring Company Award", to improve SMEs' sustainability performance, can be found in Studer et al. [48] in the context of Hong Kong. Many of these schemes are provided because small firms do not have sufficient internal resources or the expertise to implement sustainability practices on their own, and they tend to have limited access to information concerning sustainability management [49]. Egels-Zandén [50] found that implementing SSPs is an emergent and complex process, as it involves political consideration, traceability, and trade-offs in product design. Due to having limited skills, SMEs find it hard to undertake initiatives to implement SSPs on their own. Hence, support for the implementation of and apprehension about adopting SSPs could be a big factor in this regard. In addition, policy support with direct and indirect monetary benefits could be an added factor.

In short, support from and the involvement of various stakeholders, such as governments, business associations, buyers, and other stakeholders, can boost SMEs' confidence in implementing SSPs. If the stakeholders pressurize them to implement the practices without proper support, the traditional command-and-control approach would be less likely to work. Therefore, it can be proposed that:

Proposition 2a (P2a). When support from various stakeholders, such as governments and buyers, is available, SMEs are more motivated to implement SSPs. Mere pressure or law enforcement might not work for SMEs.

Such support becomes more important during a disruption that has a severe impact on the operations of SMEs. SMEs are generally more vulnerable to disruption. For example, disruption has a more severe impact on the profit and other financial measures, such as return on assets and return on sales, of SMEs than those of large corporations [51,52]. With higher impacts of disruptions and a lack of resources, SMEs find it difficult to survive and maintain SSPs. For example, a recent study [53] reported that SMEs struggle to practice social sustainability during a disruption or an extended economic crisis due to a lack of liquidity. As a result, they tend to sidestep social sustainability commitments and initiatives to ensure their survival and overcome the problem of liquidity. During such a disruption, SMEs need support from their various stakeholder groups to continue their commitment towards SSPs.

Take the example of the current pandemic outbreak of acute respiratory syndrome coronavirus 2, known as COVID-19. Organizations of all sizes, including SMEs, across the world are facing problems in retaining their workforce and maintaining social sustainability. According to the International Labour Organization (ILO), around 200 million employees globally could lose their jobs due to this extraordinary outbreak [54]. While larger firms are struggling to retain their employees and perform other sustainable practices because of continued loss $[55,56]$, it can be clearly understood how difficult it is for SMEs to retain their employees and show commitment to social sustainability. During such a crisis period, support from various stakeholder groups can serve as an incentive to practice social sustainability. The government and policymakers of a country can play a crucial role in this regard [53]. For example, Australian SMEs could access job-keeper support, an incentive provided by the government, to retain their employees [57]. Similar incentives from the government are also provided in other countries to assist SMEs in maintaining SSPs, such as retaining staff, paid leave, and other subsidies. For instance, in Cambodia, the government has contributed to the salary of the staff of SMEs who were rendered jobless because of a factory closure and confirmed their eligibility to receive 60 percent of their salary for six months [53]. The government of Sri Lanka also confirmed that employees are entitled to paid leave if factories are temporarily closed [58]. Not only the government, but other stakeholders, such as large buyers of SMEs, can also support SMEs to maintain SSPs during a disruption. Support from various stakeholder groups can give a positive impression of connectedness 
to SMEs. In return, they show their commitment to their employees and communities via performing SSPs. Therefore, we propose:

Proposition 2b (P2b). SMEs require support from various stakeholders to perform their SSPs during disruption.

\subsection{Cost Implications}

The implementation of various SSPs incurs costs for organizations. Depending on the types of costs incurred, the practices can be divided into a two-by-two matrix, showing operating cost and initial investment (Figure 1). Some practices require a high initial investment but incur low operating costs over time. For example, developing infrastructure for workplace safety and amenities, such as a cafeteria and restroom, needs substantial investment at the beginning [59]. However, once developed, the operating cost of these facilities is not too high. On the other hand, there are some other SSPs that incur high operating costs over time but need less initial investment. For instance, a firm that wants to adopt a decent pay structure for the staff may need to increase remunerations substantially [8]. In such a situation, firms need to pay additional remuneration every month. Similarly, if a firm joins with a local NGO to participate in a poverty reduction program, it may need to contribute to the program every month or year over a certain period.

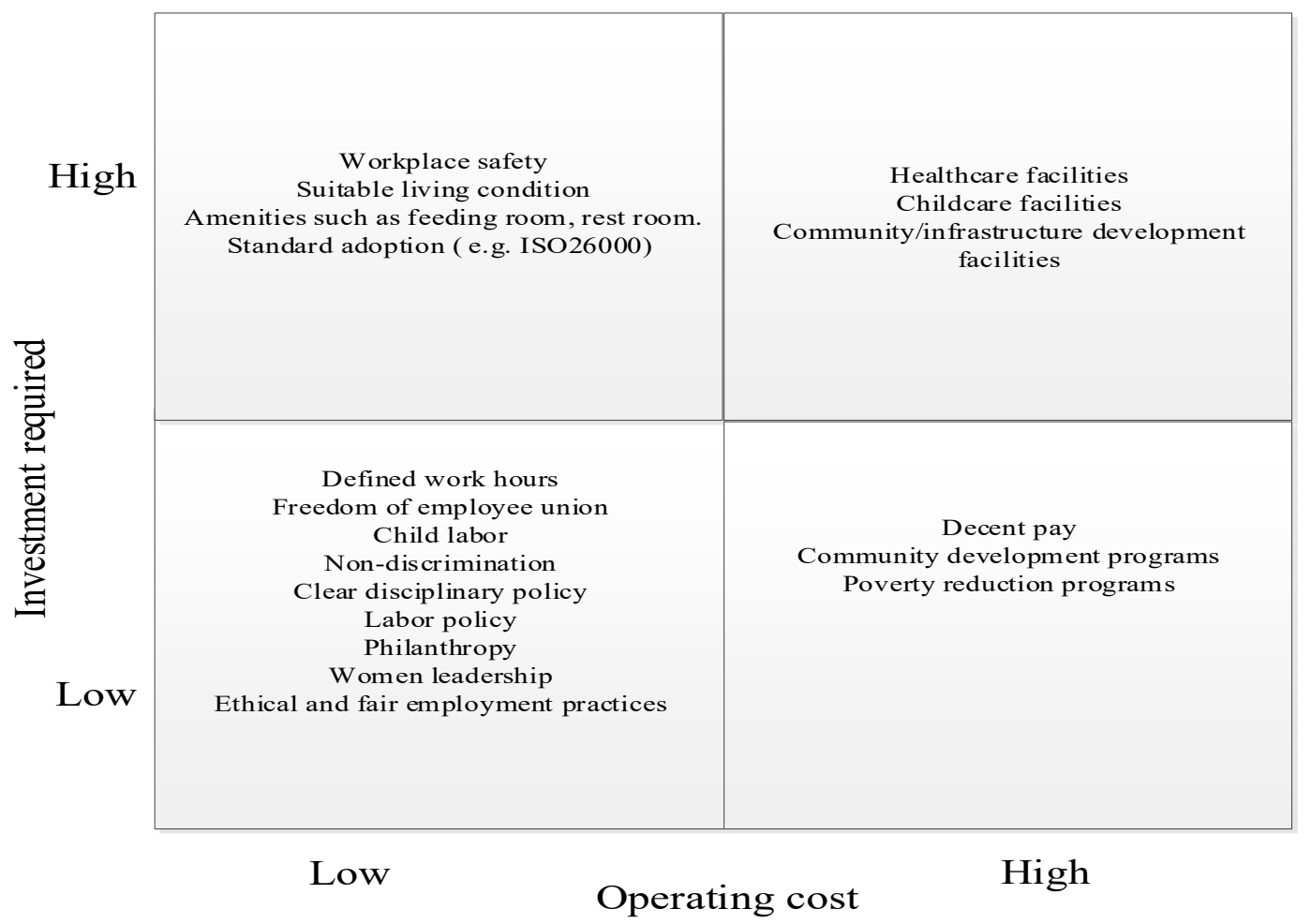

Figure 1. Social sustainability practices (SSPs) and types of cost required.

On the other hand, some practices may need both high operating costs and high initial investment. For example, if a firm wants to develop childcare facilities, first it needs to make an initial investment in developing a childcare center within the organization. Then, the firm also needs to hire one or more staff to take care of the children, which increases the operating costs for the firm. Similarly, when a firm decides to develop and run a community facility, such as a local school or health care facilities for local people, it needs to invest in the infrastructure as well as carry the running cost [11,16]. Finally, there are some SSPs that neither need high initial investment nor incur a high operating cost. Rather, these types of SSP need a proactive mindset and organizational governance structure. For example, to promote 
non-discrimination, a clear disciplinary policy, and women leadership, a firm just needs to value such practices.

SMEs face huge challenges in implementing SSPs that require a high initial investment. This is mainly because they have a lack of financial resources and are characterized by low capital [29]. It is not feasible for SMEs to make such a huge initial investment to adopt these SSPs. Moreover, SMEs face problems in obtaining compliance loans because of their lack of collateral. This challenge of SMEs is already noted in the literature. For example, the initial cost or investment is found to be one of the main barriers to why SMEs do not implement many SSPs in their businesses [41]. For adopting SSPs that need high initial investment, SMEs need financial support from other stakeholders. The support can be provided in various forms. For example, government or relevant SME policymakers, or even NGOs, can provide donations to SMEs to develop infrastructure to adopt SSPs. On the other hand, buyers can provide finance to SMEs to adopt SSPs, such as giving a certain amount to SMEs for adopting an SSP which will be later adjusted with the price of the products. In such a situation, SMEs would be able to develop infrastructure without obtaining a loan from a bank or other financial institution. Such financial support from the stakeholder is likely to encourage SMEs to do their part by adopting SSPs in the firm. Therefore, we propose:

Proposition 3a (P3a). When social sustainability implementation attracts high investment, SMEs are less likely to adopt such practices on their own; hence, they require donations, finance, or other financial support from governments or other stakeholders, such as buyers or NGOs.

When the implementation of an SSP requires a low initial investment, it is the SME's responsibility to increase the efficiency of the operation so that it can cover the increased operating cost. It is very natural that the implementation of SSPs has an impact on other enterprise functions, for example, the impact on the operating cost [37]. For example, to ensure SSPs in sourcing, firms may need to change the location of suppliers, which may incur higher transportation costs [23]. In adopting these SSPs, SMEs need to be innovative so that they can reduce the cost of the activities in their operation [60]. As an example, while SMEs implement decent pay, they can be innovative in designing shifts for the employees to maximize the use of human resources. Such an innovation in the operation can also increase productivity for the firms. SMEs should not expect that their stakeholders will provide financial assistance over the entire period needed to adopt these high operating cost-generating SSPs. Rather, they need to increase their efficiency and productivity to increase the flow of liquidity to practice these SSPs. Hence, rather than expecting financial support from the stakeholders, SMEs can seek know-how from the stakeholders so that they can efficiently implement these SSPs [61]. SMEs can also create a separate budget for covering the running cost of SSPs, as such a budget is found to be effective in implementing SSPs [62]. Based on the above discussion, we propose the following:

Proposition $\mathbf{3 b} \mathbf{b}(\mathbf{P} 3 \mathbf{b})$. When an SSP requires an increased operating cost, it is the SMEs' responsibility to increase their productivity and/or efficiency to make the SSP financially viable.

\subsection{Role of Awareness Development}

Employees' and employers' awareness both play a significant role in implementing SSPs in SMEs [46]. If the entrepreneurs of SMEs have the proper knowledge and understanding of their employees' human rights, for example, the availability of proper sanitation facilities, a safe workplace considering occupational health and safety (OHS) requirements and standards, wages paid on time, and provisions for working overtime, the implementation of SSPs becomes easier. SMEs can be opportunistic, as in many countries, the legislation for SMEs is not in place or rules of laws are not strictly maintained throughout society [48]. So, it is critical that SMEs are aware of the benefits of social sustainability in the long run to the company and to society, in addition to the ethics of business and their responsibility to society. For example, Zhang and Zhang [15] found that, 
when SME practitioners understand their role in protecting local people or the local culture, they tend to hire more local people and develop their brands with local culture, as well as train local people. Similarly, employees' awareness can make big differences as well. If the employees are aware of their rights, it is difficult for SMEs to show opportunistic behavior. They will be forced to take proper measures to ensure the health and hygiene of the workplace, pay on time, and act according to local legislation. In this regard, internal communication regarding SSPs with employees is suggested [61]. An appropriate level of education of employees could help to increase awareness regarding their rights and responsibilities. As mentioned earlier in this section, regulations are not strictly enforced in many countries, especially in developing countries; hence, awareness among employees and society is the key to social sustainability. For example, in the least developed countries, child labor is a big problem. Children are often forced to work due to the financial constraints of the family in the least developed countries, although child labor is banned in almost all the world by law. Only the awareness of both parties can help to overcome this situation where law enforcement is lacking.

Proposition 4 (P4). SMEs' and their employees' awareness may further encourage SMEs to adopt SSPS.

\section{Strategies to Handle the Mismatch Problem}

A number of strategies can be undertaken to tackle the matching problem identified in this study. We propose some strategies (shown in Table 1) that we believe are pragmatic and useful. Depending on each SME's circumstances, any or a combination of strategies could be adopted. Building a cooperative relationship is one of the most cited strategies in supply chain research and it could be very relevant in this context. The implementation and practice of social sustainability issues are complicated [50]; hence, they need support from stakeholders. The support can be in the form of receiving know-how and technical support from a stakeholder [15]. For example, when a buyer provides their requirements for SSPs, SMEs can actively seek advice, training, and assistance from the buyer for the implementation of such practices. Moreover, stakeholders can give support via providing immediate finances for implementing the SSPs. For enhancing SMEs' capabilities to practice social sustainability, various stakeholders need to extend their support via sharing knowledge and providing technical assistance and finance. In order to obtain such support, SMEs need to build trustworthy relationships with the relevant stakeholders. SMEs need to understand that support from stakeholders can only be achieved when there exists a reciprocal relationship between them. In this regard, they need to maintain their commitment to the business partners, such as by providing superior services within their capacity and sharing relevant and timely information so that a cooperative and respectful relationship is created [44].

The next strategy that we suggest to reduce the gap is undertaking awareness development programs for creating awareness in both SME owners and employees towards SSPs. We suggest this because it has been revealed that the positive attitude and orientation of SME owners/managers is one of the most crucial factors that motivates them to implement SSPs [46]. The government and other policymakers should organize campaigns and other awareness development programs to demonstrate cases (SMEs) that successfully implement SSPs. In these programs, both the benefits of SSPs and the roles of SME practitioners in implementing such practices should be highlighted. Such understanding is likely to encourage and guide them to undertake necessary actions for implementing SSPs. SMEs also need to organize internal programs for their staff so that they become aware of their roles in performing SSPs. A culture for the timely and free flow of internal communication on social sustainability should be created to develop awareness within the organization. 
Table 1. Suggested strategies for reducing the gap between stakeholders' expectations and SSPs adopted by small- and medium-sized enterprises (SMEs).

\begin{tabular}{|c|c|c|}
\hline Strategy & Implications for SMEs & Implication for SMEs' Stakeholders \\
\hline Building cooperative relationships & $\begin{array}{l}\text { Maintain commitment; } \\
\text { Information sharing; } \\
\text { Provide premium customer } \\
\text { service. }\end{array}$ & $\begin{array}{l}\text { Technical support; } \\
\text { Specific investment; } \\
\text { Training; } \\
\text { Knowledge sharing. }\end{array}$ \\
\hline $\begin{array}{l}\text { Awareness development programs } \\
\text { towards social sustainability. }\end{array}$ & $\begin{array}{l}\text { Internal communication; } \\
\text { Internal programs; } \\
\text { Knowledge development. }\end{array}$ & $\begin{array}{l}\text { Policy support by the government; } \\
\text { Demonstration of successful cases } \\
\text { (SMEs that implemented SSPs) }\end{array}$ \\
\hline Sustainable finance mechanism. & $\begin{array}{l}\text { Participation in buyers' financial } \\
\text { packages. }\end{array}$ & $\begin{array}{l}\text { Creation/development of financial } \\
\text { packages for SMEs; } \\
\text { Easy access to finance from buyer; } \\
\text { Government support in the form of } \\
\text { loan, subsidy. }\end{array}$ \\
\hline Governance structure. & $\begin{array}{l}\text { Initiative to develop corporate } \\
\text { governance structure that supports } \\
\text { social sustainability adoption. }\end{array}$ & Compliance audit for SSPs. \\
\hline Human capital development. & $\begin{array}{l}\text { Development of various programs } \\
\text { such as training, education, and } \\
\text { skill database. }\end{array}$ & $\begin{array}{l}\text { Assist SMEs in developing programs; } \\
\text { Expert knowledge sharing by buyers. }\end{array}$ \\
\hline $\begin{array}{l}\text { Implementation of innovative } \\
\text { changes. }\end{array}$ & $\begin{array}{l}\text { Efficient and innovative } \\
\text { implementation of changes. }\end{array}$ & Guide SMEs in innovative changes. \\
\hline Unified standards to follow. & $\begin{array}{l}\text { Liaise with buyers to come up with } \\
\text { standard adoption requirements. }\end{array}$ & $\begin{array}{l}\text { Develop a framework by involving } \\
\text { various stakeholders and come up } \\
\text { with a unified standard for SMEs. }\end{array}$ \\
\hline
\end{tabular}

In the literature, there is a notion that a sustainable supply chain finance mechanism could enhance sustainability practices and thus improve the sustainable performance of supply chains [63]. We propose that this could be an effective strategy to minimize the identified gap between expectation and ability. A sustainable finance mechanism is a platform where buyers come up with some financial packages for SMEs to easily access cash in return for discounted prices or any other agreed conditions. Financial institutions are invited to facilitate those packages. This mechanism can work in different ways; however, it increases the cash flow in the supply chain, which is absolutely critical for SMEs to operate. Understandably, SMEs have less access to capital and so always seek loans/credit from financial institutions, which is often difficult for them to get due to mortgages/bonds and other contractual arrangements. Financial packages from buyers in sustainable finance packages could help to build trust, collaboration, and eventually build up SMEs' confidence and motivate them to work towards implementing buyers' social sustainability requirements [63]. Therefore, the government and buyers should create a sustainable financial package for SMEs and ensure easy access to this package.

The next strategy that we suggest is maintaining a sound organizational governance structure that supports the proper implementation of SSPs in SMEs. While social sustainability fosters non-discrimination and career progression, these should be well articulated by the organizational governance mechanism. SME entrepreneurs/managers should ensure that organizational policies and processes for social sustainability issues are clear and communicated properly to the staff so that they are aware of their roles in implementing SSPs. In addition to developing a positive orientation, such clear policies and processes can also the build capabilities of the practitioners, as these may serve as a guide to improve the understanding of social sustainability issues [12]. Policymakers and governments can also play a role in this regard. For example, an audit program could be initiated to track whether SMEs properly maintain SSPs and guide them to improve such practices.

It is also essential to develop the human capital in SMEs to improve SSPs. Dynamic entrepreneur leadership is found to have a positive effect on SSPs in the context of Malaysian SMEs [32]. Such dynamic leadership or managerial competencies cannot be achieved without providing training to the 
practitioners on various issues. Therefore, SMEs need to organize various skill and knowledge development programs, such as training and education, on social sustainability for their staff. In addition, other relevant stakeholders should also help develop the human capital of SMEs. For example, buyers can provide technical support to SMEs and the government can create education programs for SME practitioners to improve their skills base on SSPs.

We also suggest that SMEs need to be innovative in changing their operations to implement SSPs. A previous study [43] showed how Metalquimia, a medium-sized family business in Spain, successfully adopted SSPs through innovation in the adoption of change. While implementing SSPs, firms may need to change their other organizational practices. For example, a firm that wants to strictly comply with maximum work hours may need to reduce the working hours of the staff. Without ensuring innovation in the operations, such as process innovation to maximize the utilization of the working hours, the cost will increase as a result of the reduced work hours of the staff. SMEs may not be able to tolerate a substantial increase in cost by adopting SSPs. The implementation of SSPs may become a burden to SMEs if they are not able to ensure innovation in the adoption of change. Therefore, SMEs need to be innovative in implementing SSPs. In this regard, various stakeholder groups, especially buyers and policymakers, should guide SMEs.

Finally, we suggest a unified social sustainability standard for SMEs to follow. The literature argues that the complexity of social sustainability standards is a major reason why SMEs do not implement SSPs. These standards are generally developed to account for international, and at least national, issues. On the other hand, SMEs act at a local level; hence, they find adopting standards to be challenging unless they are well supported by stakeholders [10]. SMEs are often required to adopt the standard certifications suggested by their stakeholders. Depending on the statutory or non-statutory obligations, stakeholders pressurize them to implement various standards, such as ISO26000, LEED, to ensure social sustainability standards are being properly followed by SMEs. There are many different types of standards required by buyers because of the local and international regulations and it is often impossible to have them all implemented due to a lack of resources. In addition, there will be a problem of fit even when they overcome the problem of the lack of resources [64]. Therefore, SMEs need a unified standard to be implemented. This will save a lot of resources, decrease the complexity of implementation, and motivate them to implement more SSPs, as the cost of implementation will be reduced greatly. Therefore, policymakers need to create a unified social sustainability standard for SMEs by involving various stakeholders. SMEs also need to provide inputs, such as requirements for buyers, so that policymakers can create a comprehensive standard to follow.

\section{Contributions of the Study}

This study investigates why there is a social sustainability gap in SMEs. It formulates some propositions and provides strategies to reduce the gap. By doing so, the study makes some notable contributions to the literature. The main contribution of this study is to identify the gaps in SMEs' SSPs and subsequent strategies, which will help the SME sector to be more socially sustainable. While previous reports broadly highlight the importance of social sustainability in SMEs and the difficulties and challenges in implementing SSPs in SMEs, none of them spotted the gap and provided a comprehensive understanding on this issue. Similarly, most of the academic articles that focus on SSPs in SMEs mainly discuss the importance, challenges, and barriers to implementing SSPs. For example, according to MacGregor and Fontrodona [43], the majority of the studies on SSPs in SMEs mostly focus on the development of awareness of SSPs. While enough justifications are already available in the literature as to why SMEs should implement SSPs, at this stage, it is more important to know the specifics of how SMEs can implement SSPs. This study discusses how social sustainability can be achieved in SMEs, which is a unique and noble contribution to the existing body of knowledge. Addressing such adequacy is important given that it is vital to know how SMEs can implement SSPs despite having resource and skill constraints and other challenges. 
Next, the study supplements the limited research focusing on social sustainability, or sustainability in general, in SMEs $[4,11,65]$. Through a systematic literature review on social sustainability, Nakamba, Chan, and Sharmina [3] reported that research to date mostly focuses on large firms, and studies investigating the practices of and approaches to social sustainability in SMEs are inadequate. Finally, the study contributes to the literature on social sustainability. While environmental sustainability has been rigorously investigated in the previous literature, research on social sustainability is scarce [7].

\section{Conclusions and Future Research Directions}

Aiming to provide guidelines to make SMEs socially sustainable, this study has explored why there is a gap between stakeholders' expectations and the SSPs adopted by SMEs, and how the gap can be minimized. Based on a rigorous literature review, the study has revealed that both internal and external factors are responsible for this social sustainability gap in SMEs. Various internal issues, such as poor organizational orientation and culture and lack of resources, skills, and knowledge, create the gap. Moreover, external factors, such as a lack of a tailored standard for SMEs and a lack of support from stakeholders, are also responsible for creating this gap or making the gap bigger. In order to minimize the gap, we propose that stakeholder support, a supply chain finance mechanism, the improvement of SMEs' efficiency and productivity, and the development of the awareness of employees will lead SMEs to be more socially sustainable. In line with these propositions, we have also provided several strategies, outlining the implications for both SMEs and their stakeholders. The strategies include building cooperative relationships with various stakeholders, developing programs to create awareness of SSPs, creating a sustainable finance package, ensuring a supportive governance structure, developing human capital, innovation in implementing SSPs, and developing a unified social sustainability standard for SMEs.

While the study findings make notable contributions to the literature, it also has a number of limitations that can be seen as the directions for future research. For example, in designing the proposition, this study only uses the current body of literature and does not consider any particular context. Therefore, future studies could empirically investigate and validate the propositions. For validating the findings of this study, a future study could formulate and test several hypotheses grounded in appropriate theories and based on the propositions suggested in this research. Moreover, a comparative study could be undertaken to explore how the proposed strategies contribute to increasing SSPs in SMEs in developed and developing countries. Such a study might provide useful information, as SSPs and their characteristics vary between developed and developing countries [4]. Moreover, there is a difference in implementing SSPs in developing and developed countries. For example, a study by Malesios et al. [18] revealed that French SMEs are different from Indian SMEs in practicing social sustainability. Therefore, a comparative study could be useful to further refine the strategies in the context of developed and developing economies. Finally, we suggest a future study for unveiling whether, how, and to what extent the strategies proposed in this research can contribute to the achievement of the sustainable development goals of the United Nations.

Author Contributions: Conceptualization, P.C. and R.S.; Literature review and information search, P.C. and R.S.; Draft writing, P.C. and R.S.; Reviewing and editing: P.C. and R.S., Administration, P.C. All authors have read and agreed to the published version of the manuscript.

Funding: This research received no external funding.

Conflicts of Interest: The authors declare no conflict of interest.

\section{References}

1. Silvestre, B.S. Sustainable supply chain management in emerging economies: Environmental turbulence, institutional voids and sustainability trajectories. Int. J. Prod. Econ. 2015, 167, 156-169. [CrossRef]

2. Mani, V.; Gunasekaran, A.; Delgado, C. Enhancing supply chain performance through supplier social sustainability: An emerging economy perspective. Int. J. Prod. Econ. 2018, 195, 259-272. [CrossRef] 
3. Nakamba, C.C.; Chan, P.W.; Sharmina, M. How does social sustainability feature in studies of supply chain management? A review and research agenda. Supply Chain Manag. Int. J. 2017, 22, 522-541. [CrossRef]

4. Mani, V.; Jabbour, C.J.C.; Mani, K.T.N. Supply chain social sustainability in small and medium manufacturing enterprises and firms' performance: Empirical evidence from an emerging Asian economy. Int. J. Prod. Econ. 2020, 227, 107656. [CrossRef]

5. European Union 2015. The Revised User Guide to the SME Definition. Available online: https://ec.europa. eu/growth/content/revised-user-guide-sme-definition-0_en (accessed on 5 May 2020).

6. Klassen, R.D.; Vereecke, A. Social issues in supply chains: Capabilities link responsibility, risk (opportunity), and performance. Int. J. Prod. Econ. 2012, 140, 103-115. [CrossRef]

7. Huq, F.A.; Stevenson, M.; Zorzini, M. Social sustainability in developing country suppliers: An exploratory study in the ready made garments industry of Bangladesh. Int. J. Oper. Prod. Manag. 2014, 34, 610-638.

8. Turyakira, P.; Venter, E.; Smith, E. The impact of corporate social responsibility factors on the competitiveness of small and medium-sized enterprises. S. Afr. J. Econ. Manag. Sci. 2014, 17, 157-172. [CrossRef]

9. Lee, C.M.J.; Che-Ha, N.; Alwi, S.F.S. Service customer orientation and social sustainability: The case of small medium enterprises. J. Bus. Res. 2020. [CrossRef]

10. Johnson, M.P.; Schaltegger, S. Two decades of sustainability management tools for SMEs: How far have we come? J. Small Bus. Manag. 2016, 54, 481-505. [CrossRef]

11. Kot, S. Sustainable supply chain management in small and medium enterprises. Sustainability 2018, 10, 1143. [CrossRef]

12. Pirnea, I.C.; Olaru, M.; Moisa, C. Relationship between corporate social responsibility and social sustainability. Econ. Transdiscipl. Cogn. 2011, 14, 36-43.

13. Mani, V.; Agrawal, R.; Sharma, V. Supply chain social sustainability: A comparative case analysis in Indian manufacturing industries. Procedia-Soc. Behav. Sci. 2015, 189, 234-251. [CrossRef]

14. Wolf, J. The relationship between sustainable supply chain management, stakeholder pressure and corporate sustainability performance. J. Bus. Ethics 2014, 119, 317-328. [CrossRef]

15. Zhang, L.; Zhang, J. Perception of small tourism enterprises in Lao PDR regarding social sustainability under the influence of social network. Tour. Manag. 2018, 69, 109-120. [CrossRef]

16. Masocha, R. Social sustainability practices on small businesses in developing economies: A case of South Africa. Sustainability 2019, 11, 3257. [CrossRef]

17. Brandenburg, M.; Gruchmann, T.; Oelze, N. Sustainable supply chain management-A conceptual framework and future research perspectives. Sustainability 2019, 11, 7239. [CrossRef]

18. Malesios, C.; Skouloudis, A.; Dey, P.K.; Abdelaziz FBen Kantartzis, A.; Evangelinos, K. The impact of SME sustainability practices and performance on economic growth from a managerial perspective: Some modeling considerations and empirical analysis results. Bus. Strategy Environ. 2018, 27, 960-972. [CrossRef]

19. Moore, S.B.; Manring, S.L. Strategy development in small and medium sized enterprises for sustainability and increased value creation. J. Clean. Prod. 2009, 17, 276-282. [CrossRef]

20. Mani, V.; Gunasekaran, A. Four forces of supply chain social sustainability adoption in emerging economies. Int. J. Prod. Econ. 2018, 199, 150-161. [CrossRef]

21. Gama, A.P.M.; Geraldes, H.S.A. Credit risk assessment and the impact of the New Basel Capital Accord on small and medium-sized enterprises: An empirical analysis. Manag. Res. Rev. 2012, 35, 727-749. [CrossRef]

22. Madanchian, M.; Hussein, N.; Noordin, F.; Taherdoost, H. The impact of ethical leadership on leadership effectiveness among SMEs in Malaysia. Procedia Manuf. 2018, 22, 968-974. [CrossRef]

23. Ciliberti, F.; Pontrandolfo, P.; Scozzi, B. Investigating corporate social responsibility in supply chains: A SME perspective. J. Clean. Prod. 2008, 16, 1579-1588. [CrossRef]

24. Borga, F.; Citterio, A.; Noci, G.; Pizzurno, E. Sustainability report in small enterprises: Case studies in Italian furniture companies. Bus. Strategy Environ. 2009, 18, 162-176. [CrossRef]

25. Ammenberg, J.; Hjelm, O. Tracing business and environmental effects of environmental management systems-A study of networking small and medium-sized enterprises using a joint environmental management system. Bus. Strategy Environ. 2003, 12, 163-174. [CrossRef]

26. Lawrence, S.R.; Collins, E.; Pavlovich, K.; Arunachalam, M. Sustainability practices of SMEs: The case of NZ. Bus. Strategy Environ. 2006, 15, 242-257. [CrossRef]

27. Lee, S.Y.; Klassen, R.D. Drivers and enablers that foster environmental management capabilities in smalland medium-sized suppliers in supply chains. Prod. Oper. Manag. 2008, 17, 573-586. [CrossRef] 
28. Karuppiah, K.; Sankaranarayanan, B.; Ali, S.M.; Chowdhury, P.; Paul, S.K. An integrated approach to modeling the barriers in implementing green manufacturing practices in SMEs. J. Clean. Prod. 2020, 265, 121737. [CrossRef]

29. Jorgensen, A.L.; Knudsen, J.S. Sustainable competitiveness in global value chains: How do small Danish firms behave? Corp. Gov. 2006, 6, 449-462. [CrossRef]

30. Mani, V.; Agrawal, R.; Sharma, V. Social sustainability in the supply chain: Analysis of enablers. Manag. Res. Rev. 2015, 38, 1016-1042. [CrossRef]

31. Clarke-Sather, A.R.; Hutchins, M.J.; Zhang, Q.; Gershenson, J.K.; Sutherland, J.W. Development of social, environmental, and economic indicators for a small/medium enterprise. Int. J. Account. Inf. Manag. 2011, 19, 247-266. [CrossRef]

32. Nor-Aishah, H.; Ahmad, N.H.; Thurasamy, R. Entrepreneurial leadership and sustainable performance of manufacturing SMEs in Malaysia: The contingent role of entrepreneurial bricolage. Sustainability 2020, 12, 3100. [CrossRef]

33. Burke, S.; Gaughran, W.F. Developing a framework for sustainability management in engineering SMEs. Robot. Comput. Integr. Manuf. 2007, 23, 696-703. [CrossRef]

34. Thakkar, J.; Deshmukh, A.K.S. Supply chain management in SMEs: Development of constructs and propositions. Asia Pac. J. Mark. Logist. 2008, 20, 97-131. [CrossRef]

35. Falkner, E.M.; Hiebl, M.R.W. Risk management in SMEs: A systematic review of available evidence. J. Risk Financ. 2015, 16, 122-144. [CrossRef]

36. Brammer, S.; Hoejmose, S.; Marchant, K. Environmental management in SMEs in the UK: Practices, pressures and perceived benefits. Bus. Strategy Environ. 2012, 21, 423-434. [CrossRef]

37. Kerr, I.R. Leadership strategies for sustainable SME operation. Bus. Strategy Environ. 2006, 15, 30-39. [CrossRef]

38. Wiesner, R.; Chadee, D.; Best, P. Insights into sustainability change management from an organisational learning perspective: Learning from SME sustainability champions. In Proceedings of the 10th International Research Conference on Quality, Innovation and Knowledge Management, Kuala Lumpur, Malaysia, 15-18 February 2011; pp. 268-281.

39. Marshall, D.; McCarthy, L.; McGrath, P.; Claudy, M. Going above and beyond: How sustainability culture and entrepreneurial orientation drive social sustainability supply chain practice adoption. Supply Chain Manag. 2015, 20, 434-454. [CrossRef]

40. Burgstaller, J.; Wagner, E. How do family ownership and founder management affect capital structure decisions and adjustment of SMEs? Evidence from a bank-based economy. J. Risk Financ. 2015, 16, 73-101. [CrossRef]

41. Castka, P.; Balzarova, M.A.; Bamber, C.J.; Sharp, J.M. How can SMEs effectively implement the CSR agenda? A UK case study perspective. Corp. Soc. Responsib. Environ. Manag. 2004, 11, 140-149. [CrossRef]

42. Maldonado-Erazo, C.P.; Álvarez-García, J.; del Rama, R.; Correa-Quezada, R. Corporate social responsibility and corporate performance in Romania. Sustainability 2020, 12, 2332. [CrossRef]

43. MacGregor, S.P.; Fontrodona, J. Strategic CSR for SMEs: Paradox or possibility? Universia Bus. Rev. 2011, 30, 80-94.

44. Chowdhury, P.; Lau, K.H.; Pittayachawan, S. Operational supply risk mitigation of SME and its impact on operational performance: A social capital perspective. Int. J. Oper. Prod. Manag. 2019, 39, 478-502. [CrossRef]

45. Gereffi, G.; Humphrey, J.; Sturgeon, T. The governance of global value chains. Rev. Int. Political Econ. 2005, 12, 78-104. [CrossRef]

46. Baden, D.A.; Harwood, I.A.; Woodward, D.G. The effect of buyer pressure on suppliers in SMEs to demonstrate CSR practices: An added incentive or counter productive? Eur. Manag. J. 2009, 27, 429-441. [CrossRef]

47. Ciliberti, F.; de Groot, G.; de Haan, J.; Pontrandolfo, P. Codes to coordinate supply chains: SMEs' experiences with SA8000. Supply Chain Manag. Int. J. 2009, 14, 117-127. [CrossRef]

48. Studer, S.; Tsang, S.; Welford, R.; Hills, P. SMEs and voluntary environmental initiatives: A study of stakeholders' perspectives in Hong Kong. J. Environ. Plan. Manag. 2008, 51, 285-301. [CrossRef]

49. Hillary, R. Environmental management systems and the smaller enterprise. J. Clean. Prod. 2004, 12, 561-569. [CrossRef] 
50. Egels-Zandén, N. Not made in China: Integration of social sustainability into strategy at Nudie Jeans Co. Scand. J. Manag. 2016, 32, 45-51. [CrossRef]

51. Hendricks, K.B.; Singhal, V.R. Association between supply chain glitches and operating performance. Manag. Sci. 2005, 51, 695-711. [CrossRef]

52. Kaufmann, L.; Carter, C.R.; Rauer, J. The coevolution of relationship dominant logic and supply risk mitigation strategies. J. Bus. Logist. 2016, 37, 87-106. [CrossRef]

53. Majumdar, A.; Shaw, M.; Sinha, S.K. COVID-19 Debunks the Myth of Socially Sustainable Supply Chain: A Case of the Clothing Industry in South Asian Countries. Sustain. Prod. Consum. 2020, 24, 150-155. [CrossRef]

54. ILO 2020. COVID-19: Impact could Cause Equivalent of 195 Million Job Losses. Available online: https://news.un.org/en/story/2020/04/1061322 (accessed on 29 June 2020).

55. Amankwah-Amoah, J. Stepping Up and Stepping Out of COVID-19: New Challenges for Environmental Sustainability Policies in the Global Airline Industry. J. Clean. Prod. 2020, 271, 123000. [CrossRef]

56. Barneveld, K.V.; Quinlan, M.; Kriesler, P.; Junor, A.; Baum, F.; Chowdhury, A.; Junankar, P.N.; Clibborn, S.; Flanagan, F.; Wright, C.F.; et al. The COVID-19 pandemic: Lessons on building more equal and sustainable societies. Econ. Labour Relat. Rev. 2020, 31, 133-157. [CrossRef]

57. Australian Small Business and Family Enterprise Ombudsman 2020. JobKeeper to Help Small Businesses Survive Coronavirus Crisis. Available online: https://www.asbfeo.gov.au/news/news-articles/jobkeeperhelp-small-businesses-survive-coronavirus-crisis (accessed on 29 June 2020).

58. Zarocostas, J. COVID-19 Crisis Triggering Huge Losses in Textile, Apparel Sector. 21 April 2020. Available online: https://wwd.com/business-news/government-trade/covid-19-crisis-triggering-huge-lossesin-textile-apparel-sector-1203566328/ (accessed on 2 August 2020).

59. Altmann, M. A supply chain design approach considering environmentally sensitive customers: The case of a German manufacturing SME. Int. J. Prod. Res. 2015, 53, 6534-6550. [CrossRef]

60. Klewitz, J.; Hansen, E.G. Sustainability-oriented innovation of SMEs: A systematic review. J. Clean. Prod. 2014, 65, 57-75. [CrossRef]

61. Henriques, J.; Catarino, J. Sustainable value and cleaner production-Research and application in 19 Portuguese SME. J. Clean. Prod. 2015, 96, 379-386. [CrossRef]

62. Burlea-Schiopoiu, A.; Mihai, L.S. An integrated framework on the sustainability of SMEs. Sustainability 2019, 11, 6206. [CrossRef]

63. Jia, F.; Zhang, T.; Chen, L. Sustainable supply chain Finance: Towards a research agenda. J. Clean. Prod. 2020, 243, 118680. [CrossRef]

64. Simpson, D.; Power, D.; Klassen, R. When one size does not fit all: A problem of fit rather than failure for voluntary management standards. J. Bus. Ethics 2012, 110, 85-95. [CrossRef]

65. Chowdhury, P.; Paul, S.K. Applications of MCDM methods in research on corporate sustainability: A systematic literature review. Manag. Environ. Qual. Int. J. 2020, 31, 385-405. [CrossRef]

(C) 2020 by the authors. Licensee MDPI, Basel, Switzerland. This article is an open access article distributed under the terms and conditions of the Creative Commons Attribution (CC BY) license (http://creativecommons.org/licenses/by/4.0/). 